Vietnam Academy of Science and Technology
Vietnam Journal of Earth Sciences
http://www.vjs.ac.vn/index.php/jse

\title{
Using the analytic signal method of gravity gradient tensor (GGT) to determine the location and depth of the faults in the Pre-Cenozoic basement rocks of the Red River trough
}

\author{
Nguyen Kim Dung ${ }^{* 1}$, Do Duc Thanh² \\ ${ }^{1}$ Institute of Marine Geology and Geophysics, Vietnam Academy of Science and Technology \\ ${ }^{2}$ Hanoi University of Science, Vietnam National University
}

Received 12 August 2015. Accepted 13 April 2016

\section{ABSTRACT}

In this paper, we present the study results of using the directional analytic signal method of gravity gradient tensor (GGT) and the Euler deconvolution of the directional analytic signals to determine location and estimate the depth of fault systems in the Pre-Cenozoic basement in order to improve the efficiency of Pre-Cenozoic basement structure. The method is tested on the 3D digital model, which shows that not only the location and depth of resources are determined but also can overcome undue interference, which could be met in the previous analytic signal methods. To study more about the applicability of the method, we applied the method for the gravity anomaly data of Red River Trough. Obtained preliminary results have shown the location of major faults in the region: Song Lo fault, Song Chay fault, Red River fault, etc. and initially (in the first time), by this method, the depth of over 10 $\mathrm{km}$ the fault persists. This depth is deeper than the depth of the surface of Cenozoic boundary determined by other methods, proves that the faults appear in the Pre-Cenozoic basement.

Keywords: Gravity gradient tensor; Euler deconvolution; fault; analytic signal.

(C2016 Vietnam Academy of Science and Technology

\section{Introduction}

Researches on the Pre-Cenozoic basement structure, especially location and depth of the fault in the basement rock determined by gravity anomalies data always get the attention of many national and international geophysicists. However, the methods used to study the structures of Pre-Cenozoic rock,me now, rock until now are still very limited in national literature. Examples are the 2D, 3D inverse problem solution methods (Do Duc

*Corresponding author, Email: kimdunggeo@yahoo.com
Thanh, 2013) and 2.5 D one, according to the correlation algorithm (Cao Dinh Trieu, 2002, Pham Nam Hung, 2011) or the method of blocks structure model of Earth's crust (Bui Cong Que and Hoang Van Vuong, 1996) in order to determine the density distribution in the basement.

To determine the location of geological faults, the most commonly used method in Geophysics is the method of determining the maximum horizontal gradient vector of gravity anomalies (Dinh Van Toan, 2000; Le Huy Minh et al., 2002). The Euler deconvolution method for the vertical derivative data of 
N.K. Dung and D.D. Thanh/Vietnam Journal of Earth Sciences 38 (2016)

gravity anomaly is used to determine not only the location but also the depth of the geological structures (Vo Thanh Son et al., 2005). The application of 3D signal analysis method (Le Huy Minh et al., 2005) and 3D signal analysis using higher derivative (Vo Thanh Son et al., 2007) initially has also been studied and are applied by these authors for analyzing and processing aviation magnetic anomalies at Tuan Giao and Hoa Binh area. The study results show that in addition to its other advantages, this method still has some limitations in overcoming the phenomenon of interference in the case of complex real environments when the differentiation of the anomalous sources is not clear.

Recently, from application of components of the gravity gradient tensor (GGT), many geophysicists have proposed a very effective method for determining the location and depth of the source (Beiki M., 2010; Beiki M. and Laust B. Pedersen 2010; Feng-Xu Z., 2005; Micku K. L., 2001; Oruc et al., 2013; Pedersen L. B. and T. M. Rasmussen, 1990; Zhang C., 2000; Zhou W., Xiaojuan Du, 2013). Therefore, the application of modern methods to determine the structure of PreCenozoic basement on the continental shelf of Vietnam is very necessary to improve the accuracy of the result.

In this paper, we studied and applied the directional analytic signals method which is built from the components of the gravity gradient tensor (ED) and the Euler deconvolution method from the direction analytic signal data (EDDAS) to determine the location and depth to faults in pre-Cenozoic basement. With this approach, we tested on the modeling to confirm the applicability of the method before applying for the real data on the Red River trough.

\section{Theoretical background}

Gravity gradient tensor (GGT) $\Gamma$ is determined as follows:

$$
\Gamma=\left[\begin{array}{lll}
\frac{\partial^{2} U}{\partial x^{2}} & \frac{\partial^{2} U}{\partial x \partial y} & \frac{\partial^{2} U}{\partial x \partial z} \\
\frac{\partial^{2} U}{\partial x \partial y} & \frac{\partial^{2} U}{\partial y^{2}} & \frac{\partial^{2} U}{\partial y \partial z} \\
\frac{\partial^{2} U}{\partial z \partial x} & \frac{\partial^{2} U}{\partial z \partial y} & \frac{\partial^{2} U}{\partial z^{2}}
\end{array}\right]=\left[\begin{array}{lll}
g_{x x} & g_{x y} & g_{x z} \\
g_{y x} & g_{y y} & g_{y z} \\
g_{z x} & g_{z y} & g_{z z}
\end{array}\right]
$$

We might define an analytic signal for every single row, called directional analytic signals in $\mathrm{x}, \mathrm{y}, \mathrm{y}-$, and $\mathrm{z}$-direction. The directional analytic signal in matrix form can be written as:

$$
\left[\begin{array}{l}
A_{x}(x, y, z) \\
A_{y}(x, y, z) \\
A_{z}(x, y, z)
\end{array}\right]=\left[\begin{array}{lll}
g_{x x} & g_{x y} & g_{x z} \\
g_{y x} & g_{y y} & g_{y z} \\
g_{z x} & g_{z y} & g_{z z}
\end{array}\right]\left[\begin{array}{l}
1 \\
1 \\
i
\end{array}\right]
$$

Consequently, the amplitudes of the directional analytic signals are:

$$
\begin{aligned}
& \left|A_{x}(x, y, z)\right|=\sqrt{\left(g_{x x}\right)^{2}+\left(g_{x y}\right)^{2}+\left(g_{x z}\right)^{2}} \\
& \left|A_{y}(x, y, z)\right|=\sqrt{\left(g_{y x}\right)^{2}+\left(g_{y y}\right)^{2}+\left(g_{y z}\right)^{2}} \\
& \left|A_{z}(x, y, z)\right|=\sqrt{\left(g_{z x}\right)^{2}+\left(g_{z y}\right)^{2}+\left(g_{z z}\right)^{2}}
\end{aligned}
$$

Debeglia and Corpel (1997) showed that the derivatives of the analytic signal amplitude give a more efficient separation of anomalies caused by interfering structures than the analytic signal amplitude. Derivatives of directional analytic signals in $\mathrm{x}, \mathrm{y}, \mathrm{y}-$, and $\mathrm{z}-$ directions can be expressed as:

$$
\begin{aligned}
& \frac{\partial\left|A_{\alpha}(x, y, z)\right|}{\partial x}=\frac{\frac{\partial g_{\alpha}}{\partial x}\left(\frac{\partial^{2} g_{\alpha}}{\partial x^{2}}\right)+\frac{\partial g_{\alpha}}{\partial y}\left(\frac{\partial^{2} g_{\alpha}}{\partial x \partial y}\right)+\frac{\partial g_{\alpha}}{\partial z}\left(\frac{\partial^{2} g_{\alpha}}{\partial x \partial z}\right)}{\left|A_{\alpha}(x, y, z)\right|} \\
& \frac{\partial\left|A_{\alpha}(x, y, z)\right|}{\partial y}=\frac{\frac{\partial g_{\alpha}}{\partial x}\left(\frac{\partial^{2} g_{\alpha}}{\partial y \partial x}\right)+\frac{\partial g_{\alpha}}{\partial y}\left(\frac{\partial^{2} g_{\alpha}}{\partial y^{2}}\right)+\frac{\partial g_{\alpha}}{\partial z}\left(\frac{\partial^{2} g_{\alpha}}{\partial y \partial z}\right)}{\left|A_{\alpha}(x, y, z)\right|} \\
& \frac{\partial\left|A_{\alpha}(x, y, z)\right|}{\partial z}=\frac{\frac{\partial g_{\alpha}}{\partial x}\left(\frac{\partial^{2} g_{\alpha}}{\partial z \partial x}\right)+\frac{\partial g_{\alpha}}{\partial y}\left(\frac{\partial^{2} g_{\alpha}}{\partial z \partial y}\right)+\frac{\partial g_{\alpha}}{\partial z}\left(\frac{\partial^{2} g_{\alpha}}{\partial z^{2}}\right)}{\left|A_{\alpha}(x, y, z)\right|}
\end{aligned}
$$

Where $\alpha$ is coefficients of $\mathrm{x}, \mathrm{y}$ and $\mathrm{z}$. Function to represent the combination of analytic signal derivatives $A_{x z}$ and $A_{y z}$ can be a function to detect the edges on the body: 
Vietnam Journal of Earth Sciences Vol 38 (2) 143-152

$$
|E D|=\sqrt{\left|A_{x z}\right|^{2}+\left|A_{y z}\right|^{2}}
$$

ED function allows to detect edges on the body better than HGA function. HGA function is a standard function which is widely used to detect edges in the horizontal gradient amplitude.

$$
H G A=\sqrt{\left(g_{x z}\right)^{2}+\left(g_{y z}\right)^{2}}
$$

Zhang et al (2000) showed that for GGT data, the standard Euler deconvolution can be extended to:

$$
\left[\begin{array}{cccc}
\frac{\partial A_{x}}{\partial x} & \frac{\partial A_{x}}{\partial y} & \frac{\partial A_{x}}{\partial z} & A_{x} \\
\frac{\partial A_{y}}{\partial x} & \frac{\partial A_{y}}{\partial y} & \frac{\partial A_{y}}{\partial z} & A_{y} \\
\frac{\partial A_{z}}{\partial x} & \frac{\partial A_{z}}{\partial y} & \frac{\partial A_{z}}{\partial z} & A_{z}
\end{array}\right]\left[\begin{array}{l}
x_{0} \\
y_{0} \\
z_{0} \\
n
\end{array}\right]=\left[\begin{array}{c}
x \frac{\partial A_{x}}{\partial x}+y \frac{\partial A_{x}}{\partial y}+z \frac{\partial A_{x}}{\partial z}-A_{x} \\
x \frac{\partial A_{y}}{\partial x}+y \frac{\partial A_{y}}{\partial y}+z \frac{\partial A_{y}}{\partial z}-A_{y} \\
x \frac{\partial A_{z}}{\partial x}+y \frac{\partial A_{z}}{\partial y}+z \frac{\partial A_{z}}{\partial z}-A_{z}
\end{array}\right] ;
$$

For a window have $\mathrm{N}$ data points, equation (9) can be written as :

$$
G m=d
$$

and can be solved using the least-squares estimate $\mathrm{m}^{\mathrm{est}}$ as follows:

$$
m^{\mathrm{es} t}=\left(G^{T} G\right)^{-1} G^{T} d
$$

Where $\mathrm{G}$ and $\mathrm{d}$ are $3 \mathrm{~N} \times 4$ and $3 \mathrm{~N} \times 1$ matrices. Then the residual error of data is:

$$
\Delta d=d^{\text {pred }}-d
$$

where : $\quad d^{\text {pred }}=G m^{\text {est }}$

Then the covariance matrix of the estimated model is given as:

$$
\begin{gathered}
{\left[\operatorname{Covm}^{\mathrm{es} t}\right]=\sigma_{d}^{2}\left(G^{T} G\right)^{-1}} \\
\text { where } \sigma_{d}^{2} \cong \frac{\sum_{i=1}^{N}\left(\Delta d_{i}\right)^{2}}{N} \text { and } \\
{\left[\text { Covm }^{\mathrm{est}}\right]=\left[\begin{array}{llll}
c_{11} & c_{12} & c_{13} & c_{14} \\
c_{21} & c_{22} & c_{23} & c_{24} \\
c_{31} & c_{32} & c_{33} & c_{34} \\
c_{41} & c_{42} & c_{43} & c_{44}
\end{array}\right]}
\end{gathered}
$$

and the standard error of source location and structural index is given by:

$$
\Delta r_{0}=\sqrt{c_{11}+c_{22}+c_{33}} ; \Delta n=\sqrt{c_{44}} ;
$$

\section{Modeling and results}

\subsection{Building of the model}

To confirm the applicability of the method using the directional analytic signals of the components of the gravity gradient tensor (ED) to determine the location and depth of the faults in Pre-Cenozoic basement rock for in case of the 3D problem, on the basis of the theory presented above, we proceed to build a computer program to determine edges and depth as the source by gravity anomalies data. Here, the source of the gravity anomaly was modeled as vertical cylinders located at different depths. To see clearly the effectiveness and applicability of the method, we launched two models to calculate: The first model has 2 single objects; the second model is more complex, consisting of 5 objects that can cause anomaly and having both local and regional properties, in which the anomalies caused by

\begin{tabular}{|c|c|c|c|}
\hline $\mathrm{X} 1 / \mathrm{X} 2$ & $\mathrm{Y} 1 / \mathrm{Y} 2$ & $\mathrm{Z} 1 / \mathrm{Z} 2$ & $\begin{array}{c}\text { Excess density } \\
\left(\mathrm{g} / \mathrm{cm}^{3}\right)\end{array}$ \\
\hline t $1 \overline{65 / 75}$ & $75 / 85$ & $1 / 5$ & 0.2 \\
\hline Object $275 / 85$ & $65 / 75$ & $2 / 5$ & 0.2 \\
\hline
\end{tabular}
5 th objects have large size and lie deeper than other objects. Observation surface for both

\begin{tabular}{|c|c|c|c|}
\hline $\mathrm{X} 1 / \mathrm{X} 2$ & $\mathrm{Y} 1 / \mathrm{Y} 2$ & $\mathrm{Z1/Z2}$ & $\begin{array}{l}\text { Excess density } \\
\left(\mathrm{g} / \mathrm{cm}^{3}\right)\end{array}$ \\
\hline$\overline{\text { Object } 1} \overline{30 / 40}$ & $75 / 85$ & $1 / 4$ & -0.1 \\
\hline Object $265 / 75$ & $75 / 85$ & $1 / 6$ & 0.2 \\
\hline Object $375 / 85$ & $65 / 75$ & $2 / 6$ & 0.2 \\
\hline Object $4110 / 120$ & $65 / 75$ & $2 / 6$ & 0.3 \\
\hline Object 5 50/100 & $50 / 100$ & $6 / 12$ & 0.4 \\
\hline
\end{tabular}
models has a size of $150 \times 150 \mathrm{~km}$ and the distance between two data points in both two directions $\mathrm{x}$ and $\mathrm{y}$ is $\mathrm{dx}=\mathrm{dy}=1 \mathrm{~km}$. The parameters of the model are given in (tables 1 and 2). The programming language used is Matlab.

Table 1. The parameters for model 1

Table 2. The parameters for model 2 
N.K. Dung and D.D. Thanh/Vietnam Journal of Earth Sciences 38 (2016)

\subsection{The result of model application}

The assumed gravity anomalies which are caused by the prisms having the parameters as above were determined by Rao and Murthy, 1990, ED function is calculated for each point on the surface $\mathrm{z}_{0}=0$. In order to point out the advantages of the method using the ED function in determining edges over the source, we also calculate HGA function on this observation surface. For both functions, the line connecting maximum points will give us the edges of the source.

To estimate the depth to edges from the source, we used Euler method of deconvolution of the directional analytic signals combined with slide windows method in which the center of the window is maximum ED points. The use of this data is different compared to the use of other sources of data, which are the components of the gravity tensor or using higher vertical derivatives ( $\mathrm{Vo}_{\mathrm{O}}$ Thanh Son et al., 2005; Vo Thanh Son, Le Huy Minh, 2007). In Euler deconvolution method, the structure index and size of the window are two important parameters, which decide the accuracy of the method. Each structural indicator characterizing certain geological objects, so depending on the studied objects that the structural indicators are selected suitably. The window size also affects the resolution of study depth and therefore, is selected to represent the effect on a single source type which should be studied. The problem of structure index and size of the window, and how to choose them reasonably is studied by many national and international authors (Reid AB et al., 2013; Vo Thanh Son, Le Huy Minh, 2005). Usually, the author only chooses an unique structure index (as a source filtering), however, in this article, the edges from the source have been determined by the maximum ED points, so in these maximum points. There will have many structure indexes, according to the equation (16), each maximum ED point will have one structure indicator. To solve this problem, at each maximum ED point we need a loop to find the most structure index which corresponds with the depth to edges with the smallest error. In order to stabilize the data error, the authors select one structure index $=0.05$ and put it into structure index space. The selected structural indicators are assigned to directly into 4th component of the vector in the equation (13) before calculating covariance matrix equation (14). With the pre-assigned structure index the obtainment of conversed result is more rapid, avoiding the re-solution at positions, which have unstable structure index or depth outside the selection. Results also showed that the study depth obtained for both models is best when the selected window size is 14 points, $w x=w y=14$. Thus, the issue of the Euler deconvolution by this way, from depending on two parameters (the structure index and size of the window) becomes only depending on one parameter (the size of the window). This makes a difference in compare with the Euler deconvolution methods that are often used (Vo Thanh Son et al., 2005). Calculation results for model 1 are shown in Figure 1 and Figure 2. Figure 1 shows the results of determination of the edges from the source by both ED and HGA function, and Figure 2 shows the results of determination of the depth to the edges of source using Euler deconvolution of the directional analytic signals (EDDAS).

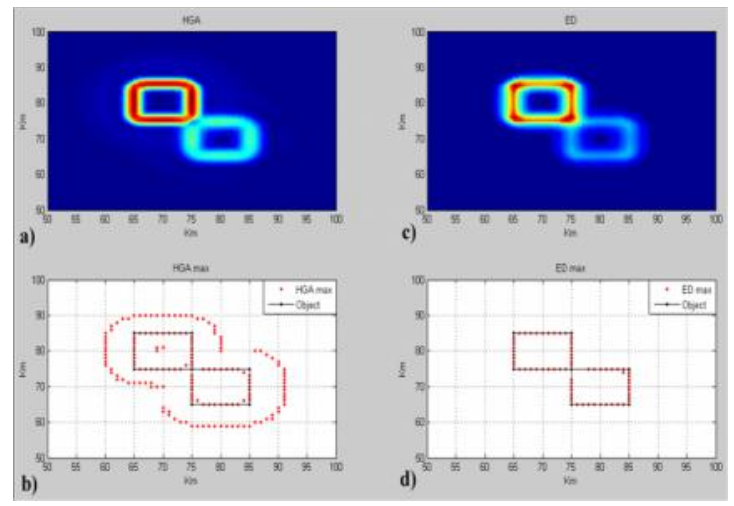

Figure 1. The results determine source edges for model 1: a) Function HGA, b) Maximum HGA, c) Function $E D$, d) Maximum ED 
Vietnam Journal of Earth Sciences 38 (2016) 143-152
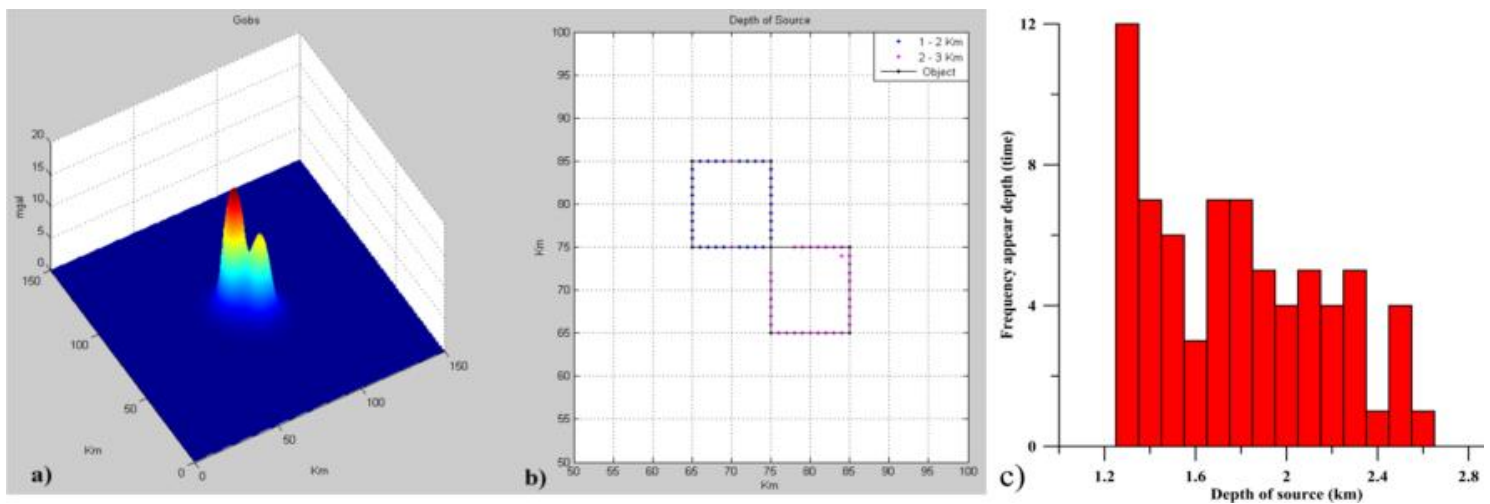

Figure 2. The results of the source depth for model 1: a) Observation data, b) Depth of source, c) Frequency appear depth
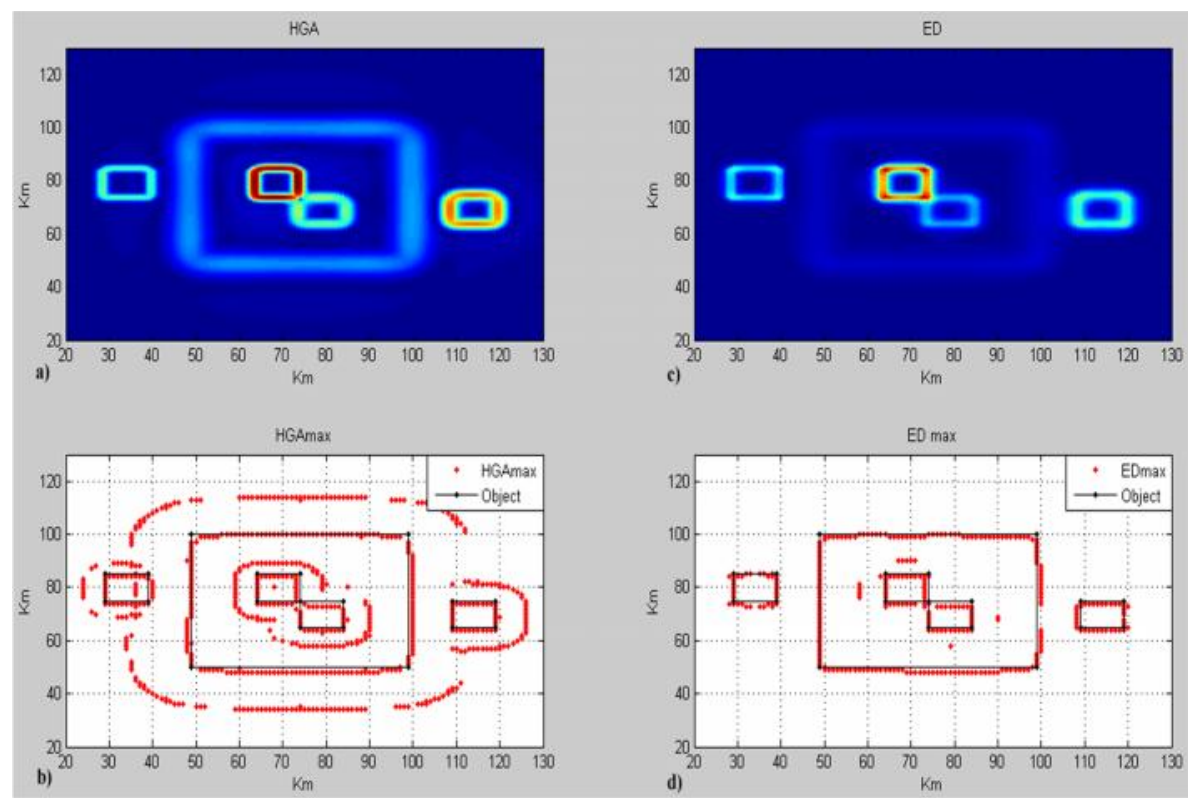

Figure 3. The result determine source edges for model 2: a) Function HGA; b) Maximum HGA; c) Function ED; d) Maximum ED
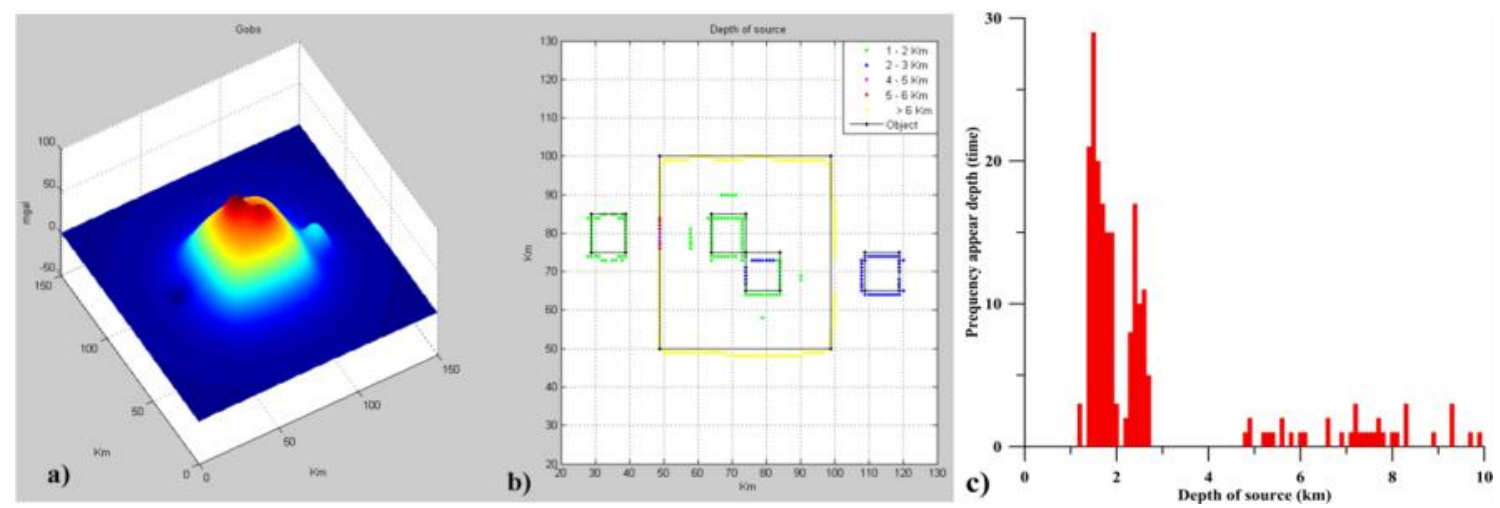

Figure 4. The result of the source depth for model 2: a) Obesrvation data; b) Depth of source; c) Frequency appear depth 
N.K. Dung and D.D. Thanh/Vietnam Journal of Earth Sciences 38 (2016)

Calculation results for model 2 are shown in Figure 3 and Figure 4, in which the positions of calculated result are arranged respectively as shown in Figure 1 and figure 2.

\subsection{Discussion}

Based on the results obtained from the program construction and test on models from simple to complex, we can give the following comments:

- Despite fairly complex algorithm, the use of analytic signal method under the direction of the components of the gravity gradient tensor (ED) and applied to the computer programs we built still allows to determine the edge and to estimate the depth of source.

- The determination of the edges of source by using the maximum ED method gives the higher accuracy than by using the traditional maximum HGA method. Specifically, signal maximum ED tackles the phenomenon of interference better than a signal maximum HGA when the objects cause anomalies, which have weak differentiation on both horizontal and vertical directions.

- The use of the Euler deconvolution method to determine the depth of source by this way has overcome the dependency on the structure index.

\section{Applying the method to determine the location and estimate the depth of the faults in Pre-Cenozoic basement rocks of the Red River trough}

In this section, based on the computer programs set up and tested on the digital model, we conducted a test by applying the directional analytic signals method of gravity gradient tensor (ED) and the Euler deconvolution of the directional analytic signals to determine location and estimate the depth to edges of source in the Red River trough. Herein, the study area is bounded by latitudes $20^{\circ} 9.8^{\prime} \mathrm{N}$ and $21^{\circ} 35.7^{\prime} \mathrm{N}$ and by longitudes $105^{\circ} 6.5^{\prime} \mathrm{E}$ and $106^{\circ} 37.1^{\prime} \mathrm{E}$. The data source
(Input data) used in this research was the Bougher gravity anomaly data of the study area at the scale of 1:200,000 which was established by the Department of Geology and Minerals of Vietnam in 1995 based on the normal gravity field formula of Helmert (1901-1909). The gravity anomaly data had been edited and linked to the Posdam International standard system with the density of intermediate layer $\delta$ $=2.67 \mathrm{~g} / \mathrm{cm}^{3}$; terrain correction was calculated by the Prisivanco method.

The Red river trough is characterized by a quite complex geological-tectonic setting and there are many major faults such as Song Lo fault, Vinh Ninh fault, Thai Binh fault, Song Chay fault and Red River fault. All faults have the direction of northwest - southeast and parallel to each other; they form a large tectonic destruction system and penetrate through the Earth crust. They play an important role in the map of regional tectonic structure and create a ladder-like structure which has uplifted zones alternating with subsidence zones, expand and sink into the southeast. In many previous studies, the trough of Hanoi was divided into three main structural zones: The southwest structural zone, which is an uplift zone, locates between two deep regional faults, which are the Red River fault and the Song Chay fault. The center structural zone is limited by Song Chay fault and Song Lo fault, which are plugging in opposite directions. Between these two faults, the Thai Binh and the Vinh Ninh faults are also plugging in opposite directions. All these faults create a SouthWestern-Northeast wave band that characterizes the structure of the region. Northeast structural zone is limited by Dong Trieu fault and Song Lo fault and is an uplift structural zone comparing to the Center structural zone. There were many books and researches discussing fault systems, regional tectonic characteristics in this area such as Phan Trong Trinh et al., 2000; Phan Trong Trinh, 2012; Cao Dinh Trieu and Pham 
Nam Hung, 2008; Nguyen Dang Tuc, 2000; Nguyen Dang Tuc, 2004; Hoang Huu Hiep and Nguyen Huu Nam, 2014,... Therefore, we will discuss on the geological characteristic in general and focus on research of fault systems in the region in detail.

To study the deep source, especially in the Pre-Cenozoic basement rocks, we increased the height of the field by $8 \mathrm{~km}$. At this surface, the obtained gravity anomaly field was partly separated to the local gravity anomaly field which had a short wavelength so the gravity effect mainly depends on the depth sources. This alternative anomaly field will be used to determine location and depth to the source. During calculation process, parameters of the selection structure index and the window size used to calculate are the parameters which were selected and tested by the above models. The obtained results of the location and the depth to the edge of a resource in the study area by applying this method (ED and EDDAS) are represented on Figure 5, showing the points with different colors. In this figure, a position of a point reflects an edge of the source, and its color shows the depth of source with various intervals. To highlight the structure within the study area, the system of these colored points is presented by vertical quadratic derivative values of the gravitational field Gzz (only Gzz $>0$ ) and of the horizontal gradient vector field of Gzz function (arrows). In this method, we separated the study depth into six different segments: 0-2 km, 2-4 km, 4-6 km, 6-8 km, 8$10 \mathrm{~km}$, and $>10 \mathrm{~km}$. The recorded results showed that locations of major faults in the study area were expressed quite clearly as Song Lo fault, Vinh Ninh fault, Song Chay fault, Thai Binh fault, Red River fault, etc. All faults were in northwest - southeast direction, paralleled to each other and were recognized easily by observing the maximum ED points and the horizontal gradient vectors of the Gzz function in the same direction. The results also illustrated that gradient vectors of the 2nd vertical derivative of Song Lo fault and Thai Binh fault ran along the maximum ED points in southwest - northeast direction, while the gradients of Song Chay fault and Vinh Ninh fault were almost in northeast southwest direction (Figure 5). In addition, the uplift zones (with gradient vector of the Gzz function directing into the center) including Hanoi center uplift, Kien Xuong uplift and Nam Dinh uplift and the subsidence zones (with gradient vector of Gzz function directing outward the center) Ninh Binh sunken, Hai Duong sunken, Dong Quan Sunken also was found in the area. Comparing to the previous study results, this result shows that the location of the fault system in the study area is quite similar. Therefore, the application of the maximum ED points to determine edges of the source is effective.

The result of depth shows that the depth of source in the research area is from 3 to $17 \mathrm{~km}$, mainly at $6 \mathrm{~km}$ and that of major faults are greater than $8 \mathrm{~km}$. These obtained depth values may be the depth of the top or the bottom of a source, or the depth which crosses another source that is a picture of a geological cross-section. However, where is the existence and appearance of the sources, in the Pre-Cenozoic basement or the Cenozoic sediment? To study sources existing in the Pre-Cenozoic basement, we compare the depth values determined by seismic and gravity methods to the depth of Pre-Cenozoic basement (Pham Nam Hung and Le Van Dung, 2011). In results, the depth values along the major faults can lie on or under the Pre-Cenozoic basement surface, this indicates that a complex development of the fault is not only on the surface but also in depth and confirms the appearance of faults in the PreCenozoic basement.

According to Cao Dinh Trieu (2002), the faults in the Pre-Cenozoic basement which continue to develop and penetrate to crust are: Red River Fault (over 60km), Song Chay fault $(35-40 \mathrm{~km})$, Song Lo fault $(30-40 \mathrm{~km})$, Vinh Ninh fault $(20-30 \mathrm{~km})$. Because the data source is limited, in this article, we only apply the method to study the appearance of the 
N.K. Dung and D.D. Thanh/Vietnam Journal of Earth Sciences 38 (2016)

sources which lies in the Pre-Cenozoic basement, and we will not discuss about the bottom depth of this fault. To recognize faults exactly, we digitized Figure 5 according to the maximum ED points and the results are shown in Figure 6.
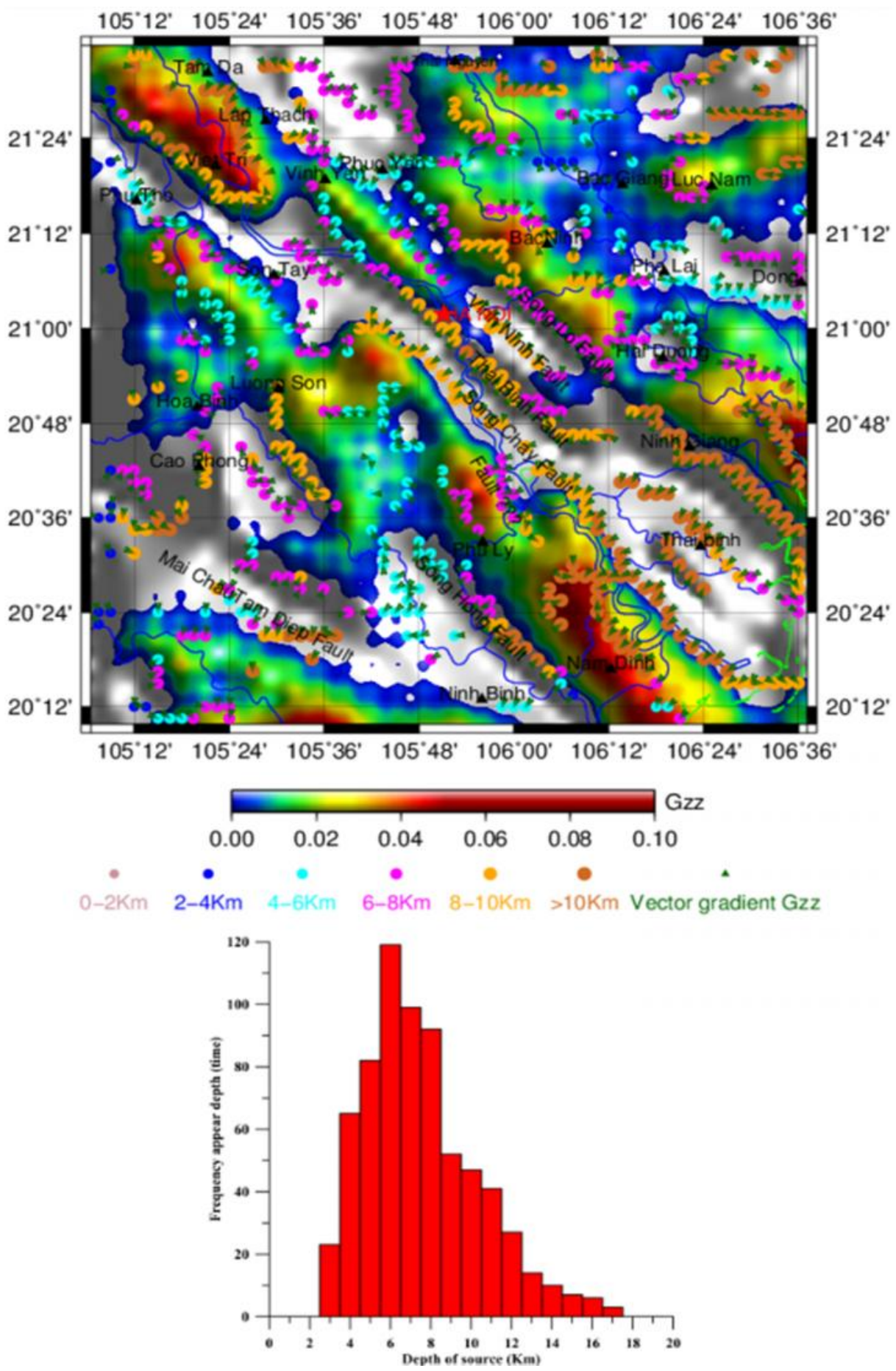

Figure 5. The location and estimate depth of source and frequency appear depth at $\mathrm{z}=8$ 
Vietnam Journal of Earth Sciences 38 (2016) 143-152

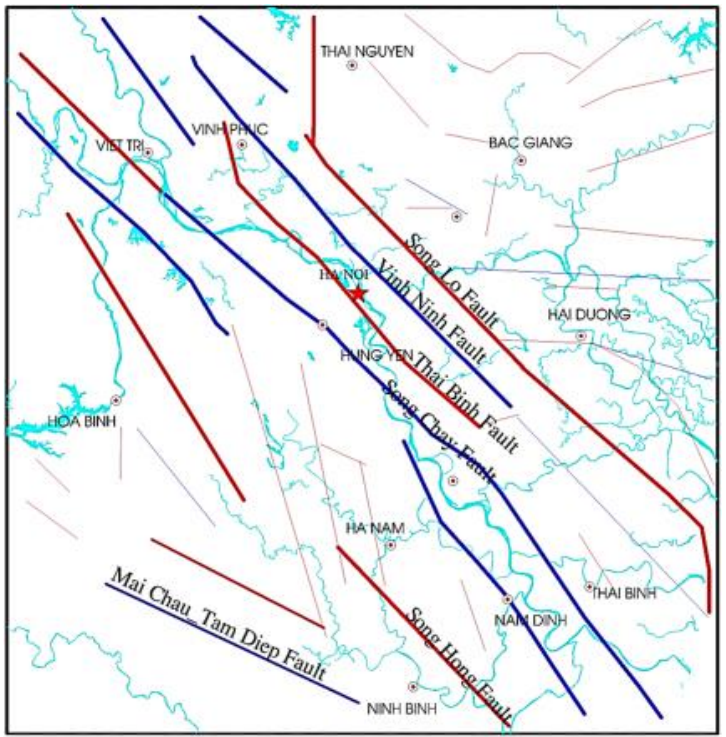

Figure 6. The faults obatian by maximum of function ED

\section{Conclusions}

Based on the results obtained from the program construction, test on models and application the real data of the Red River trough, we can give few comments as follows:

- Using analytic signals of a gravity gradient tensor (GGT) method to determine the ED of the directional analytic signals amplitude function helps overcome the phenomenon of interference and provide better resolution than the HGA of traditional analytic signal amplitude function. It is a new method to determine the accurate location and estimate the depth of fault systems.

- As the object of this study is the faults in the Pre-Cenozoic basement rock, a combination of processing methods for gravity data including transformative method of gravity field, the analytic signal methods, and Euler deconvolution for data of the directional analytic signals of gravity gradient tensor were used, which allows not only to identify the location but also estimate the beginning depth and the end depth of the fault, so that we can estimate the depth, strike and dip angle of the fault exactly and rapidly.
- Results of the test on the area of the Red River trough show that the method can determine the major faults in the region. Moreover, the method also illustrates that the faults found at depths over $8 \mathrm{~km}$, even to $15 \mathrm{~km}$, are the faults destroyed in the Pre-Cenozoic basement.

- Although there are a lot of advantages, applying many times derivative in the method makes many error peaks during calculation at the surface $\mathrm{z}=0$. To solve this problem, we can calculate the average of gravity field or raise gravity anomaly field before calculation in detail.

\section{Acknowledgments}

The authors wish to thank to project VAST06.01/15-16 had support necessary conditions to complete this article.

\section{References}

Mickus,K.L., Juan Homero Hinojosa, 2001. The complete gravity gradient tensor derived from the vertical component of gravity: a Fourier transform technique. Journal of Applied Geophysics 46, 159-174.

Beiki M, 2010. Analytic signals of gravity gradient tensor and their application to estimate source location. Geophysics, Vol.75, No.6, 159-174.

Beiki M, 2011. New techniques for estimation of source parameters. Uppsala Universitet.

Beiki M., Pedersen, L.B., 2010. Eigenvector analysis of gravity gradient tensor to locate geologic bodies. Geophysics 75, I37-I49.

Bhaskara Rao, D., Prakash, M.I., and Ramesh Babu, N., 1990. 3 and D modeling of gravity anomalies with variable density contrast. Geophys. Prosp, Vol.38, 411-422.

Blakely, R. J., and R. W. Simpson, 1986. Approximating edges of source bodies from magnetic or gravity anomalies: Geophysics,51, 1494-1498,doi: 10.1190/1.1442197.

Bui Cong Que, Hoang Van Vuong, 1996. Investigation on the density distribution of Pre-Cenozoic fundament in the South - East Viet Nam shelf by the volumetric structural modelling method of the Earth crust. Proceeding of marine geology and geophysics study works, Vol, 2, Publisher of Science and Engineering, 1996, 277-285.

Cao Dinh Trieu, Pham Huy Long, 2002. Tectonic fault in Vietnam. Publisher of Science and Engineering. 
N.K. Dung and D.D. Thanh/Vietnam Journal of Earth Sciences 38 (2016)

Cao Dinh Trieu, Pham Nam Hung, 2008. Some characteristics of the geological structure in the Cenozoic in southwest of Hanoi trough based on data analysis of gravity and other geological-geophysical data.

Debeglia, N., and J. Corpel, 1997. Automatic 3-D interpretation of potential field data using analytic signal derivatives. Geophysics,62, 87-96, doi:10.1190/1.1444149.

Do Duc Thanh, Nguyen Kim Dung, 2013. Determine density contribution of basement rock by modeling of 3D gravity inversion. Journal of Sciences of the Earth, 35, 1, 47-52.

Feng-Xu,Z, Ling-Shun, M., et al., 2005. Calculating normalized full gradient of gravity anomaly using hilbert transform . Chinese journal of geophysics, vol.48, No.3, 777-784.

Hoang Huu Hiep, Nguyen Huu Nam, 2014. Geometrical characteristics and kinetic mechanism of the fault system in the center of Hanoi trough and their role in the formation and destruction of Cenozoic structural traps. Journal of the Oil and Gas, Vol. 9, 26-32.

http://www.idm.gov.vn/nguon_luc/Xuat_ban/2008/A305/a24.htm

Le Huy Minh, Luu Viet Hung, 2003. Preliminary interpretation for the map of magnetic anomaly on the East Sea and adjacent areas. Journal of Sciences of the Earth, Publisher of Science and Engineering, $\mathrm{Ha}$ Noi, 25, 2, 173-181.

Le Huy Minh, Luu Viet Hung, Cao Dinh Trieu , 2001. Modern methods from magnetic data analysis applied to Tuan Giao area. Journal of Sciences of the Earth, Publisher of Science and Engineering, Hanoi, 22, 3, 207-216.

Le Huy Minh, Luu Viet Hung, Cao Đinh Trieu, 2002. Using the maximum horizontal gradient vector to interpret magnetic and gravity data in Vietnam. Journal of Sciences of the Earth, Publisher of Science and Engineering, 24, 1, 67-80.

Le Huy Minh, Vo Thanh Son et al., 2005. The threedimensional analytic signal method application to interpret the aviation magnetic anomaly map in Tuan Giao. Proceedings of the 4th geophysical scientific and technical conference of Vietnam. Publisher of Science and Engineering 2005.

Nguyen Dang Tuc, 2000. Kinematic characteristics of the Red River - Chay River fault zone in Cenozoic, J. Sciences of the Earth, Ha Noi, 22, 3, 174-180.

Nguyen Dang Tuc, 2004. The operational characteristics of the red river Fault Zone. http://www.idm.gov.vn/nguon_luc/Xuat_ban/2004/A285/a69.htm.

Nguyen Hiep, 2005. Geology and Vietnam oil and gas resource. Vietnam Oil and Gas Company (Petrovietnam).
Oruç, B., Keskinsezer, A., 2008. Structural setting of the Northeastern Biga Peninsula (Turkey) from tilt derivatives of gravity gradient tensors and magnitude of horizontal gravity components. Pure Appl. Geophys. 165, 1913-1927.

Oruç, B., Sertcelik, I., Kafadar, O., Selim, H.H., 2013. Structural interpretation of the Erzurum Basin, eastern Turkey, using curvature gravity gradient tensor and gravity inversion of basement relief. J. Appl. Geophys. 88, 105-113.

Pedersen, L. B., and T. M. Rasmussen, 1990. The gradient tensor of potential field anomalies: Some implications on data collection and data processing of maps. Geophysics,55, 1558-1566, doi: 10.1190/1.1442807.

Pham Nam Hung, Le Van Dung, 2011. The deep structures of Hanoi region and adjacent areas on the basic of gravity data analysis. Journal of Sciences of the Earth, Vol.33, No.2, 185-190.

Phan Trong Trinh, 2012. Young tectonics and modern geodynamics in Vietnam sea and adjacent areas. Publisher Natural sciences and technology.

Phan Trong Trinh, Hoang Quang Vinh, Nguyen Dang Tuc, Bui Thi Thao, 2000. Young tectonic activity of the Red River Fault Zone and adjacent areas. Journal of Sciences of the Earth, 22, 4, 325-336.

Reid,A.B, et al., 2013. Avoidable Euler errors - the use and abuse of Euler deconvolution applied to potential fields. European association of geoscientists \& engineers, Geophysical Prospecting.

Schneider. M, R.Stolz, S.Linzen, M.Schiffler, A.Chwala, M.Schulz, 2013. Inversion of geo - magnetic full - tensor gradiometer data. Journal of Applied Geophysics 92, 57-67.

Vo Thanh Son, Le Huy Minh et al., 2007. Determining the location and depth of the contrast magnetic boundaries by using the $3 \mathrm{D}$ analytics signal method and higher derivatives. Proceedings of the 4th geophysical scientific and technical conference of Vietnam, 136-147.

Vo Thanh Son, Le Huy Minh, Luu Viet Hung, 2005. Determining the horizontal position and depth of the density discontinuities in the Red River Delta by using the vertical derivative and Euler deconvolution for the gravity anomaly data. Journal of Geological, series A, Vol.287, 3-4, 39-52.

Zhang C., M. F. Mushayandebvu et al., 2000. Euler deconvolution of gravity tensor gradient data. Geophysics,65, 512-520, doi: 10.1190/1.1444745. 